Karadeniz Uluslararası Bilimsel Dergi

Volume: 41, Spring-2019, p. 120-135

ISSN: 1308-6200 DOI Number: 10.17498/kdeniz.478428

Research Article

Received: November 4, $2018 \quad$ Accepted: January 14, 2019

This article was checked by iThenticate.

\title{
BOLU MÜZESİ'NDEN BİR GRUP ROMA DÖNEMİ KORİNTH BAŞLIĞI
}

\section{A GROUP OF ROMAN PERIOD CORINTHIAN CAPITALS FROM BOLU MUSEUM*}

\section{ГРУППА КОРИНФСКИХ КАПИТЕЛЕЙ РИМСКОГО ПЕРИОДА ИЗ БОЛИЙСКОГО МУЗЕЯ}

\begin{abstract}
Akın TEMÜR** - Merve ÇELIK ${ }^{* * *}$
Öz

Klasik dönemde ortaya çıkan korinth başlığı Roma İmparatorluğu'nda oldukça sevilmiş ve yoğun olarak kullanım görmüştür. Bu çalışmada Roma İmparatorluğu yapılarının tasarımları, kullanılan yöntemler, kentteki mimari düzenlemeler, kamu yapıları ve işlevleri esas alınarak; Roma dönemine ait Bityhnion sikkeleri üzerindeki betimlemelerden de yola çıkarak, kentte var oldukları anlaşılan, korinth düzenindeki sütunlu yapılara ait olması gereken başlıkları kapsamaktadır. İmparatorlukta Hadrian dönemiyle Anadolu'da yoğun olarak yaşanan imarlaşma hareketleri, Severuslar döneminde de devam etmiş ve bu imarlaşma hareketleri Bithynion kentinde de gözlemlenmiştir. Kent özellikle Hadrian döneminde Antinoos'un doğduğu yer olması nedeniyle ayrıcalıklara sahip olmuş ve mimari yapılaşmanın daha da yoğunlaştığ 1 görülmüştür. Bolu Müzesi envanterinde bulunan korinth başlıkları da bu yapılaşmanın en önemli kanıtlarından biridir. Yapılan kazı ve araştırmalar sonucu, Bolu kentindeki pek çok mimari yapıdan elde edilen korinth başlıklarından, müzeye getirilmiş olanları, araştırmanın esas konusunu oluşturmaktadır. Bu çalışmayla söz konusu yapılarda süsleme ögesi ve taşıyıcı eleman olarak işlev görmüş korinth başlıklarını, stil özellikleriyle ele alıp lokalizasyon sorununun çözümlenmesi amaçlanmıştır. Bu kapsamda kentin Roma İmparatorluk dönemindeki sosyo-ekonomik yapısı, siyasi ve dini değerleri de dikkate alınarak çalışmalar yürütülmüştür. $\mathrm{Bu}$ çalışmalar sonucunda korinth başlıklarının; stil gelişimleri ve kompozisyonları içerisinde birçok farklı dönem özelliklerini gösterdiği tespit edilmiş ve bu kapsamda üç tip altında gruplandırılan başlıklar, dönemsel gelişimlerine göre ayrılmıştır.
\end{abstract}

Anahtar Kelimeler; Bolu Müzesi, Bithynion, Bithynia Bölgesi, Korinth Başlığı, Roma Mimarlı̆̆

\footnotetext{
* $\mathrm{Bu}$ çalışma, Ondokuz Mayıs Üniversitesi, Bilimsel Araştırma Geliştirme Destekleme Programı (PYO.FEN.1904.18.031) tarafindan desteklenmiştir.

** ORCID: 0000-0001-9777-5256 Dr. Öğr. Üyesi, Ondokuz Mayıs Üniversitesi, Fen-Edebiyat Fakültesi, Arkeoloji Bölümü, Samsun, akintemur@yahoo.com

*** ORCID: 0000-0002-6915-7343 Y.L.Öğr., Ondokuz Mayıs Üniversitesi, Sosyal Bilimler Enstitüsü, Arkeoloji Anabilim Dalı, Samsun, mervecelik014@gmail.com
} 


\begin{abstract}
Having emerged in the classical period, Corinthian capitals were very popular and widely used in the Roman Empire. Based on designs of Roman Empire structures, methods used, architectural arrangements in the city, public structures and their functions, and based on the depictions on Bityhnian coins belonging to the Roman period, this study covers capitals that are thought to exist in the city and that must belong to colonized structures in the Corinthian order. Intensification movements occurring in Anatolia during the reign of Hadrian in the Empire also continued during the Severan period, and these movements were observed in the city of Bithynia. The city had privileges being the birthplace of Antinoos during Hadrian period, and architectural structuring was more concentrated. Corinthian capitals found in the Bolu Museum inventory are also one of the most important evidences of this structuring. As a result of excavations and studies conducted, among Corinth capitals obtained from many architectural structures in the city of Bolu, those brought to the museum constitute the main subject of research. The aim of this study is to discuss style characteristics of Corinth capitals that functioned as a decoration element and carrier element in structures in question, and to address problem of localization. In this context, studies were carried out considering socioeconomic structure, political and religious values of the city during the Roman Empire period. As a result of these studies, it was determined that Corinthian capitals show characteristics of different period in their style developments and compositions, in this respect, these capitals were grouped under three types and divided according to their periodic developments.
\end{abstract}

Keywords: Bolu Museum, Bithynion, Bithynia Region, Corinthian Capitals, Roman Architecture

\begin{abstract}
Аннотация
Коринфские капители классического периода были очень популярны в Римской империи. В нижеследующей исследовании на основе методов в архитектуре, строения общественных структур и городского строя Римской империи, включая изображения на Битвинийских монетах римского периода было установлено, что они относились капительям колонной структуре Коринфского порядка. Строительствення деятельность в Анатолии при правлении Адриана продолжался и в период Северуса, которое отразилось и в Битвинии. Город был привилегированным в период Адриана в связи с тем, что там родился Антиноос и архитектурные постройки были более интенсивными. Коринфские капителы из музея Болу являются одним из важнейших доказательств этой постройки. Итоги раскопок по направлению Коринфких капителей и архитектурных сооружений города Болу размещённых в музее, являются основным предметом нашего исследования. Цель нижеследующей статьи, решение проблемы локализации путем исследования элементов орнамента и стилистических характеров коринфских капителей. В этом контексте были проведены исследования с учетом социально-экономической структуры, политических и религиозных ценностей города в период Римской империи. В результате этих исследований капителы коринфа по своему стилью, композиции, различных особенностей и периода строения, были сгруппированы по трем типам и разделены в соответствии с их периодическим развитием.
\end{abstract}

Ключевые слова: Музей Болу, Битвиния, Битвинийский край, Коринфский капител, Римская архитектура. 


\section{Giriş}

Bithynion (Bolu); Bithynia bölgesinin önemli kentlerinden biri olup, Nikomedia'dan Pontus ve Paphlagonia bölgelerine doğru giden önemli bir yol güzergâhı üzerinde bulunmaktadır (Sevin 2001, 39). Plinius'un (Plinius IX, 1938-1971) Historia Naturalis adlı eserinde, Bithynium-Claudiopolis olarak geçen kentin kalıntıları, günümüzde Bolu kent merkezinde yükselmektedir. En erken yerleşim izlerinin Eski Tunç Çağına kadar uzandığı kentin, ilk sakinlerini Hititler oluşturur. Sonrasında sırasıyla Friglerin ve Lydialıların hakimiyetine geçen kent, Lydialıların M.Ö. 546'da Persler'e yenilmesiyle birlikte Pers valileri tarafından yönetilmeye başlar. Sonrasında Prusias (M.Ö. 227-182) tarafından şehir (polis) yapılır. Claudius'un iktidarda olduğu dönemde (M.Ö. 54-41) ise, kentin adı Claudiopolis olarak değiștirilir. Hadrianus (M.S. 117-138) döneminde, muhtemelen Hadrianus'un gözdesi Antinoos'un doğduğu bu kente, tanınan birçok ayrıcalıklardan dolayı Hadrianon Kladiopoleiton adı verilir (Marek 2003, 74-80). M.S. 3. yy.'ın 2. yarısında kentin adı tekrar Claudiopolis olarak değiştirilir ve M.S. 384'de Honorias eyaletinin başkentliğini yapar. Bizans Döneminde kent büyük ölçüde önemini kaybederek prokonsüller tarafından yönetilmeye başlar (Umar 1986, 37).

\section{Korinth Başlığının Ortaya Çıkışı}

Çalışmaya konu olan korinth başlığının ilk olarak Mimar Kallimachos tarafından M.Ö. 440'larda keşfedildiği kabul edilir (Vitruvius 2005, 77). Bitkisel bir form esas alınarak oluşturulan başlık (Başaran 1995, 10), abakus levhası altındaki sepet biçimindeki bir kalathos ve üzerine yerleştirilen alt ve üst yaprak çelengini oluşturan akanthus yapraklarından oluşmaktadır. Üst yaprak çelengini oluşturan akanthus yaprakları arasından, halka biçiminde boğumlu bir boyuna sahip, çanak biçiminde iki yana açılan bir kaulis yaprağı çıkmaktadır. Kalathos üzerinde ise, ortası çiçekli abakus levhası bulunur. Kenarları iç bükey olan ve dörtgen formlu levhanın ortasında genellikle abakus çiçeği bulunur. Abakus levhasının alt köşelerinde volütler ve yaprak ortalarında helezon yapan heliksler, başlığın temel formunu oluşturur (Kramer 1997, 22-23). Bu şekliyle korinth başlığı hem üst yapının taşıyıcı bir elemanı olarak hem de bezemeli bir mimari eleman olarak karşımıza çıkar (İdil 1984, 2).

\section{Roma Dönemi Korinth Başlıklarının Genel Gelișimi}

M.Ö. 5 yy. sonunda Yunanistan'da ortaya çıkan korinth başlı̆̆ı, Roma İmparatorluk dönemi sonuna kadar farklı yapılarda karşımıza çıkar (Yılmaz 2010, 70-71; 2012, 694). Klasik dönemde iç dekorasyonda, dış mimaride ise ilk olarak anıtlarda daha sonra tapınaklarda görülmeye başlayan korinth başlı̆̆ (Başaran 1997, 4), Hellenistik dönemden itibaren Anadolu mimarisinde gösterdiği zengin süsleme ile ait oldukları yapıya estetik görünüş sağlayan taşıyıcı bir mimari elemana dönüşür (Söğüt 2005, 161-177). Bu döneme ait başlıklarda başlık uzun ve kalathos tektonik bir biçimde oluşturulmuştur. Yapraklar kalathos gövdesine yapışıktır ve üzerinde derin yuvarlak kıvrımlı, dolgun damarlar bulunmaktadır. Akanthus yapraklarının henüz yeterince biçimlenmediği yaprak dilimleri arasında; ovalimsi, yuvarlak ve kalp biçiminde gözler ile sivri uçlu yaprak dişleri bulunmaktadır (Sezgin 2004, 11). Başlığın orta-üst bölümünde kalathos oldukça belirgindir. Heliks ve volüt sapları güçlü, kaulisler ise, uzun kanallı ve kalındır. Bu başlık ögeleri hellenistik dönem etkisi ile kalathos yüzeyine ne sıkı sıkıya yapışmış ne de ondan belirgin bir biçimde ayrılmıştır. Bununla beraber, başlıklar genel görünüşleri ile oldukça geniş ve serttir. Akanthus yapraklarının daha belirgin bir biçimde kıvrılmaları ise, M.Ö. 1. yy.'ın 
ortalarına ait bir özellik olarak karşımıza çıkar. Agustus dönemiyle birlikte ise, en çok kullanılan mimari düzene dönüşür (İdil 1984, 2).

Geç Augustus dönemi ve Tiberius'un (Sögüt 2005, 353) erken dönemlerinde, kalathosu sıkıca saran akanthus yaprakları başlığa derinlik kazandırırken, kolay kırılabilecek çatallı ve yarıklı bir yüzeye sahip olmaları ve yaprak dilimleri arasındaki yuvarlak gözlerin kaba bir dudakla çevrilmiş olması gibi yeni özellikler ortaya çıkmaya başlar. Claudiuslar dönemine gelindiğinde korinth başlıklarında sivri dişli alt sıra akanthus yapraklarının birbirlerinden ayrıldığı görülür. Bu dönemde ince damarlı, hafiff̧e katlanmış olan akanthus yapraklarının üst bölümleri, kalathosun üzerinden dışarıya doğru biraz sarkmaktadır. Yaprak uçlarının kıvrılarak, aralarında ters dönmüş kalp biçimi oluşturmaları ise, yeni bir özellik olarak karşımıza çıkar. Uzun formlu olan başlıklarda heliksler daha çok dekoratif özellik gösterirlerken, volütlerle aralarında dar açı oluştururlar (İdil 1984, 9-10). Flaviuslar dönemi korinth başılılarının en belirgin özelliği; başlık ögelerinin oldukça serbest yapılmış olması ve kaulislerin olmamasıdır. Akanthus yapraklarındaki yaprak dilimleri arasındaki gözler ise, damla şekline dönüşmüştür (Güzel 2007, 15-16). Derin yüzeyler ve akanthus yaprakları üzerindeki ışık-gölge etkisi daha gelişkin bir yapı ortaya koyar (Baranaydın 2016, 32). Bu özellikler Batı Anadolu'da M.S. 1. yy.'ın ortalarından başlayıp, 2. yy.'ın başlarında da devam eder (İdil 1984, 15).

Hadrianus ile Antoninus Pius döneminin başlarında Batı Anadolu'da özellikle Bergama ve Efes'te bulunan birçok korinth başlı̆̆ı, formlarının açıklı̆ğ ile ön plana çıkar. Kalathos üstünün dil kalıpları biçimindeki yapraklarla kaplandığı bu başlıklarda (Heilmeyer 1970, 18, Taf. 9,1) alt sıra akanthus yaprak sırasını oluşturan on iki adet akanthus yan yana dizilmiştir. Derin biçimde kalıplandırılarak matkapla işlenen bu yapraklar, kalathos yüzeyinden öne doğru çıkmış gibi görünmektedir (Yener 2014, 132). Antoninus Pius dönemi başlarında Hadrian dönemi özelliklerinin devam ettiği görülür (Şimşek-Sezgin 2007, 114 fig. 12). Bu sebeple geç Hadrianus ile erken Antoninus dönemi sanatı arasında kesin bir çizgi belirlemek oldukça güçtür (Başaran 1997, 10).

Geç Antoninus Pius ile erken Severuslar döneminin stil özelliklerinin başında; yaprakların alttan geniş bir şekilde başlayan ve taç yaprağına doğru gittikçe daralan orta damarının her iki yanında ikişer yaprak dilimine ve taç kısmına yer verilmiş olması gelir. Alt ve üst yaprak dilimleri dört parmağa sahiptir. Yaprak dilimleri içerisinde, yaprak kaidesinden başlayarak parmak uçları içerisine kadar uzanan, derin ve geniş kanallar bulunmaktadır. Sivri olan parmak uçlarından başlayarak, yaprak dilimleri içerisinde bulunan kanallara doğru parmakların içe doğru eğimli oldukları ve derin bir çizgi hattı ile yivlendirildiği gözlenmektedir. Taç yaprağından aşağıya, orta damarın her iki yanından ise birer kanal inmektedir. Yaprakların parmak kısımları kısa, dar, ancak uçları oldukça sivridir. Dilimler içerisindeki parmakların bir tanesi, üst yaprak diliminin alt parmağına dokunurken, birleşilen alanlarda üçgene benzeyen, yarıklar şeklinde gözler oluşmaktadır. Kaulis kökleri yuvarlak ve yüksek bir forma sahipken, kökler matkabın yoğun bir şekilde kullanımı sayesinde spiral halinde, ince ve derin bir şekilde yivlendirilmiştir. Diğer yüzlerdeki kaulis kökleri ise yivsizdir. Benzer bir durum kaulis düğümleri için de söz konusudur. Kaulis köklerinden bir tanesi üzerinde, aşağı doğru asılı ve üç bölümlü yaprak dizisi ile bezenmiş düğümler yer alırken, diğer düğümler, bilezik formunda ve süslemesizdir.

Kaplama yapraklarına baktığımızda oldukça büyük, güçlü ve dik bir şekilde çıkan bir yapıya sahip olduğunu görürüz. Kaplama yapraklarının alt kısımlarından itibaren başlayan derin oyuklu yivler yukarı doğru yükselerek, parmak uçlarının içlerine kadar uzanmaktadır (Kaplan 2016, 158). Çan biçimli kalathosun bu ilk evrede belirginleşen taban bileziği üzerine sıkça dizilmiş alt sıra akanthus yaprakları, sivri yaprak dişleriyle bağlanmış ve Antoninus Pius döneminde görülen küçük kapalı ara boşluklar sayıca çoğalarak kalathos 
yüzeyini bir ağ gibi sarmıştır. Tek sıralı yaprak dişleri hem kendi içinde hem de diğer akanthus yapraklarıyla birleştirilmiş, böylece de iki akanthus arasında beş gözlü bir oyuk oluşmuştur. Akanthus yapraklarında yaprak damarları derinliğini kaybederken, yayvan yaprak dilimleri yüzeyselliklerini korumuştur. Yaprak dişlerinin birbirlerine ve ara yapraklara ince bantlarla bağlanması, aralarda göz göz alanların oluşması bu dönemin genel stil özelliği olarak karşımıza çıkar. Akanthus yapraklarındaki doğallıktan uzak ve bozulmuş stil, kaulis ve helikslerde de görülür. Akanthusun üstünden bir çanaktan çıkan kaulisler belirsiz işlenmiş, buna bağlı heliks kökü kıvrık dal, heliks ise ucu düğümlü yarım palmet görünümü kazanmıştır. Kaulis çanağına kadar indirilen yassı bantlar, köşelerde volüt oluştururken, abakus çiçeğinin sapı akanthuslara kadar dalgalı bir biçimde inmektedir. Bütün bu özellikler M.S. 185-190 yılları arasında izlenebilen genel stil özellikleri olarak karşımıza çıkmaktadır (Başaran 1997, 16).

Geç Antoninus-Erken Severuslar dönemi stil özelliklerinin başında; yaprakların, alttan geniş bir şekilde başlayan ve taç yaprağına doğru gittikçe daralan orta damarının her iki yanında, ikişer yaprak dilimi ve taç kısmının olması gelir. Alt ve üst yaprak dilimleri dört parmağa sahiptir. Yaprak dilimleri içerisinde, yaprak kaidesinden başlayarak yaprak ucu içerisine kadar uzanan, derin ve geniş kanallar mevcuttur (Kaplan 2016, 158). Severuslar dönemi stilinin en belirgin özelliği ise, iri yüzeysel bezekler ve bozulmuş, kaba işçiliktir (Başaran 1995, 158; 1997, 13-14). Kalathosa gömülmüş akanthuslarda izlenen stil, Severuslar döneminin başlangıç özelliklerinden biridir. Yaprakların genişlemesi ve ardından M.S. 3. yy.'nn başlarında yoğun olarak karşılaşılan derin oyulmuş kanallar belirgin stil özelliklerinin başındadır (Başaran 1999, 31). Severuslar dönemi stilinin biraz daha netleştiği örneklerde alt sıra akanthusların birbirine bağlanmasıyla oluşan göz göz oyulmaların sayısı artmıştır. Akanthus yapraklarını birbirine bağlayan köprüler ikiden üçe çıkmış, dördüncü için zemin hazırlanmıştır. Akanthus dilimlerinin ince ipçiklerle birbirine bağlanması sonucu oluşan dantelsi görünüm ve yaprak yüzeylerinin iç bükey oyulmaları bu döneme özgü bir yenilik olarak karşımıza çıkar (Başaran 1999, 32).

Geç Antik Çağ korinth başlıklarında Severuslar döneminin getirdiği yüzeysellik ve basit işçiliğin doruk noktasına ulaştığı görülür.

Dönemin karakteristik özelliklerinin başında alt sıra akanthus kuşağının yaprak dikenlerinin birleşmesi ile oluşan boşluk alanların bombeli dörtgen form kazanması ve sertleşmesi gelir. M.S. 3. yy. stilinde kaulis ve helikslerde izlenen yalınlaşma, belli belirsiz bir yapı kazanan abakus çiçeği sapı ile olabildiğince yüzeysel biçimde kalathos üzerini kaplayan akanthus yaprakları, bozulmuş bir stilin yansımalarıdır. Akanthusların birbirlerine yaprak uçlarından kalın bantlarla bağlanması sonucu oluşan göz göz oyulmalar sayıca azalmış olmasına karşın daha geniş bir alana yayılmıştır. M.S. 3. yy. başlarında bezemelerdeki doğal yapının yok olması ve bozulma ile birlikte aşırı matkap kullanımı, bezemede parçalanmanın meydana gelmesine yol açmıştır. Ardından durgun ve kaba hatlara dayalı aynı çizgilerin hakim olduğu bir stil evresine geçilmiştir. Bu evreninin en erken örneklerinde sivri uçlarını kaybetmeye başlayan akanthuslar, oldukça yüzeysel işlenmiş ve yaprak dişleri arasındaki göz göz boşluklar yayvan çanaklara dönüştürülmüştür. Klasik biçimini kaybeden akanthuslarda ortadaki yaprak dilimi, tabana doğru genişlerken, temel özelliklerinden sıyrılan heliksler ve abakus çiçeği sapı yapraklaşmış bir biçim göstermeye başlamıştır. Bu dönemin en önemli yeniliği ise, kalathos taban bileziği üzerine ionik kymanın yerleştirilmiş olmasıdır. Bu özellikler dönem içinde yaygınlaşarak, 3. yy. ortalarında geç antik dönemin yerleşik stiline dönüşmüştür (Başaran 1999, 49). Yüzeyselliğin son aşamaya ulaştığı örneklerde ise, ayrıntılar tümüyle kaldırılmıştır. En önemli stil özelliği, tabanda birbirine bağlı yaprak dişlerinin arasında oluşturulan, kenarları içe bombeli dörtgen alandır. Daha önceki örneklerde bu alan üçgen bir biçim gösterirken, burada yaprak uçlarının 
kıvrılmaları sonucu dört köşe bir boşluk meydana gelmiştir. Bu açıdan sonraki başlıklar için öncü niteliğinde olan başlıklar M.S. 3. yy. sonuna tarihlenir.

Geç Antik dönem için belirleyici özelliklerden bir diğeri; alt akanthus yapraklarının birbirlerine bağlanmaları sonucu tabanda oluşan, dörtgen alanın yeni bir aşama kazanmış olmasıdır. Bu özellik, M.S. 4. yy. başına ait bir stil özelliğidir. Balık pulu çizgileri ile bezeli abakus tablası üzerindeki abakus çiçeği ve sapı, üst sıra akanthus yaprak aralarında birleşen volüt kökleri ve yüzeysel işçilik ise M.S. 4. yy. içerisinde yeni bir evrenin habercisidir (Başaran 1997, 20-21). Stil açısından en geç örneklerin ortası damarlı olup, akanthuslar oldukça yüzeysel ve tabana doğru genişleyen bir eksen yaprağına sahiptir. Alt yaprak dilimlerinin birbiri içine girmesi ile değişik biçimlerde içi boş alanlar oluşmuş, akanthus yan yaprakları arasında da geniş boşluklar meydana gelmiştir. Akanthus yaprak dilimleri alev şeklinde, sivri uçlu bir yaprak görünümündedir. Volüt kökünden çıkan dörtlü palmetler iki yandan giyoş bandı sınırlanmış ve abakus profili tümüyle ortadan kalkmıştır. Bu özellikler M.S. 5-6. yy. başlıklarındaki stil evresini yansıtır (Başaran 1997, 15, Lev. 14 $\mathrm{a}-\mathrm{b})$.

\section{Bolu Müzesi Korinth Başlıkları}

Bolu Müzesi bahçesinde sergilenen korinth başlıkları, Bithynion antik kentinin Roma İmparatorluk döneminde yapılmış olup 8 adet sütun çalışma kapsamınına alınmıştır. $\mathrm{Bu}$ başlıklar beyaz ve gri olmak üzere mermerin iki ayrı tipinde yapılmış olup, hem küçük hem de büyük ölçekli yapılara aittir. Başlıklar arasında ölçü, malzeme ve tarih olarak farklı örneklerin tespit edilmiş olması, korinth düzenindeki yapıların çoğunluğunu ve yaygınlığını ortaya koymaktadır. Anadolu'da M.S. 2 yy.'da bazı korinth ve kompozit başlıklarının yapımında, Hadrian döneminden başlayarak çoğunlukla yerel atölyeler tarafından, kısmen Anadolu'daki büyük yapı dekarasyonu atölyelerinden ya da okulların eserlerinden esinlenilmiştir (İdil 1984, 33).

Bithynion kentinin yerleşim bölgesi, Osmanlı döneminde de olduğu gibi bugün de aynı işleve sahip olan kent merkezidir (Karagülle 2015, 6, ek 1). Günümüze ulaşmış yapı temelleri kısmen görülebilmektedir. Kenttin ana yerleşimi üç bölgeye dağılmış olup bunlar; Hisartepesi, Kargatepesi ve Fırkatepesi olarak kayıtlara geçmiştir. Günümüze kadar yapılan araştırmalar ve yazılı kaynaklar (Yalman 1981, 449-450) neticesinde saptanan bulgulara göre; İmparator Traianus (M.S. 98-117) zamanında Seben Dağı yakınında kaplıcalar yapılmıştır. M.S. 2. yy.'da Hadrian döneminde muhtemelen Hisartepesi'nde Hadrian Tapınağı (?), Hisartepesi'nin eteklerinde stadion, Bizans dönemi kilise, nekropol alanı Fırkatepesi'nin güneyinde tiyatro, Kargatepesi'nde; kentin agorası ve ikinci tiyatronun yapıldığı bulgulardan anlaşılmaktadır (Dimicioğlu 2012, 2, şek. 2,4).

Kalıntılar halinde günümüze kalan tapınakların şekillerini Anadolu'da bulunan sikkeler üzerindeki tasvirlerde bulmak mümkündür (Yalman 1981, 205; Dimicioğlu 2012, 6). Yapının kendisi konuyu oluşturduğundan sikkenin darbedildigi sırada yapılmış olan veya eskiden beri var olup da devam eden yapıları gösteren tasvirlerdir. Sikke yuvarlağının tümünü kaplayan yapılar, olabildiği kadar aslına yakın ve detaylı gösterilmişlerdir (Anabolu 2016, 1). Zaman zaman sikkeler üzerinde görülen tapınakların cephe sütun sayıları değiştirilmiş olmasına rağmen gerçekte 8 sütunlu tapınaklar 8 sütunlu nadiren de 10 sütunlu gösterilmiştir (Ara 1971, 47-48). Bithynia bölgesinde de Hadrianus tarafından bastırılan bronz ve gümüş sikkelerin bir yüzünde 8 sütunlu tapınak, ön yüzünde Hadrianus'un profilden portresi işlenmiştir (Tekin 2012, 269). Anadolu'da yapılan 8 sütunlu tapınaklar genellikle dipteros veya pseudodipteroslarda kullanılmıştır (Ara 1971, 47-48).

Çalışmaya konu olan başlıklara baktığımızda Kat. No. 1, 2, ve 6 no ile gösterilen korinth başlıklarının geç Hadrianus-Antoninus Pius dönemi özelliklerini yansıttığını, 
akanthusların aralıklı olarak dizildiklerini görürüz. İkinci sıra akanthus yaprakları ise, kendi aralarında birleşerek birinci sıra akanthus yapraklarına çerçeve oluşturmuş̧ur (Heilmeyer 1970, Taf. 21.1). Taş çıkıntıdan başlayarak yükselen ikinci sıra akanthus yaprakları birinci sıra akanthus yaprakları ile birlikte sıkı bir biçimde yerleştirilmişlerdir. Birbirine yakın olan yaprak dişlerinin yüzeyi örtmesiyle 1şı-gölge etkisi oluşturulmuş ve derinlik kazandırılmıştır. Kaulis çanağı oldukça yüksektir. Akanthus yapraklarında belirgin bir geometrik betimleme hakimdir. Gövdesi tamamen akanthus yaprakları ile kaplanmış olan bu sütun başlığı tipi, M.S. 2. ve 3. yy.'da genellikle Doğu Roma'da oldukça yaygın olup, Aphrodisias'ta yoğun olarak üretilmiştir. Bunda Anadolu'da özellikle Trajan döneminde, sanatsal faaliyetlerin ve imarın gelişmiş olması ve Aphrodisias civarında zengin mermer yataklarının olması önemli bir rol oynar (Fischer 1990, 41).

Geç Hadrianus ve Erken Antoninler dönemi başlıkları keskin özelliklerle ayrılamadığından geçiş dönemi başlıkları olarak ayrı grup içinde değerlendirilmektedir. Başlıklara baktığımızda kalathos tabanına aralıklı yerleştirilen akanthus yapraklarının fazla derin olmayan kanallı damarlarla vurgulanmış olduğu, yaprak dilimlerinin de yayvanlaşarak 1şık-gölge etkisini yitirmeye başladığını görürüz. Araları bezemesiz bırakılan heliksler ince kıvrımlardan soyutlanarak, ortada bir düğmeye bağlanmış, kaulis çanaklarının dış kıvrımlarıyla oluşturulan çanaktan çıkan abakus çiçeğinin sapı ince bir ip görünüm almıştır. Kalathos üzerinde yer yer boşluklar oluşmuş ve bezemedeki etki kaybolarak barok bir yapı egemen olmuştur. Akanthus yapraklarının kalathos üzerine yayılması, yaprak damarlarının dar işlenişi, yaprak dişlerinin sivrilmesi ve yer yer diğerleriyle bağlanmasıyla küçük kapalı boşlukların oluşması M.S. 140-150 arasına ait stil özelliği olarak karşımıza çıkar (Başaran 1997, 11). Severuslar dönemi korinth başlıkları özelliği olan alt yaprak uçlarının birbirleri ile temas etmesi, Geç Antoniler dönemi özelliği olarak da karşımıza çıkmaktadır (Kaya 2016, 126).

Kat. No. 3, 4, 5 ve 7 nolu korinth başlıklarını incelediğimizde; akanthus yapraklarının üç yaprak dişi ile birbirine bağlanmış olduğunu, kalathosun yelpaze şeklindeki yapraklarla neredeyse tamamen örtülmüş olduğunu görürüz. Suriye ve Anadolu dekorasyonunun kombine stili ve geometrikleşmesi burada net bir şekilde görülür. Başlıkların kalathos zemini üzerinde, birbirini takip eden kare, üçgen ve eşkenar dörtgen biçiminde Bizans sütun başlıklarını yansıtan geometrik stil özellikleri görülmektedir. Yaprakların birbirine değmesiyle oluşan köprüler, yaprağı enine ve boyuna çaprazlar ve loblar ana köprüde eğrileşir. M.S. 2. yy.'da Anadolu' daki sütun başlıklarının genel gelişimini belirleyen bu özellikler (Fischer 1990, 51-52), Anadolu'da bulunan sütun başlıklarında sıkça karşımıza çıkar.

Severuslar dönemi korinth başlıklarının karakteristik özelliklerinin başında ise, genel olarak sıkışı, kendi aralarında ve birbirleri ile birleşen akanthus yaprakları gelir. Bunlar başlığı sararak dantel görünümünü oluşturur. Üst yarıda oldukça sıkışan kaulis, heliks ve volütler dönem özelliklerini göstermektedir (Kaya 2016, 126).

Kat. No. 8 nolu korinth başlığı ise, M.S. 3. yy. özelliklerini yansıtmaktadır. Volütler alçak kabartma, hafif basık ve incedir. İnce profilli abakusun ön cephesinde kalathosa kadar uzanan büyük bir abakus çiçeği, çoğu zaman üst yapraklardan yükselen burgulu bir sap tarafından taşınmaktadır (Fischer 1990, 48). Bu grubun en önemli özelliği ise, heliksin tamamen kaldırılmış olmasıdır. Bu durum başlığın üst kısmının görünüşünü tamamen değiştirmiştir. Kalathosla birlikte şekillendirilmiş olan volütler, direk kalathostan çıar gibi betimlenirken, volütler düz, spirallerin ucu ise helezon şeklindedir. Kaulisler tamamen kaybolmuş, kaulis çanakları ise, erken örneklerde olduğu gibi şekillendirilmiştir. Helikslerin olmaması, volütlerin şematik gösterilmesi, ince yapılmış abakus levhası ve büyük abakus çiçeği oldukça önemli stil özellikleridir. Benzer mimari elemanlarla stil birlikteliği 
gösterebilecek olan başlıklara M.S. 5. yy'a'da rastlanmaktadır. Bu başlıklarda abakus çiçeği farklı stil özellikleri göstermektedir. Birbirlerine yakın uçların bağlantısı, alt ve üst yaprak uçları, heliksler ve abakus çiçeği dekoratif mimari elemanlar haline gelmiştir. Bu da kaulisi veya kaulis çanağı olmayan başlıkların ortaya çıkmasına neden olmuştur. Tüm bu özellikler M.S. 5. yy.'da mimaride en çok görülen stil özelliklerinin başında gelir (Fischer 1990, 51$54)$.

\section{Sonuç}

Kral yönetiminde küçük bir şehir olan Roma, hızla gelişerek önce İtalya, Avrupa sonra da Afrika ve Asya kıtalarına kadar genişlemiştir. Cumhuriyet Döneminden sonra İmparatorluk Dönemi ile Anadolu'daki kent devletleri Augustus'tan başlayan İmparatorluk kültüyle tanışmıştır. Bithynion antik kenti de gerek Antinoos'un doğum yeri olması gerekse İmparatorluk kültü gibi siyasi propagandaların uygulanması nedeniyle ayrıcalıklı bir kent olmuştur. Anadolu'da Hadrian ve Severuslar dönemiyle birlikte yoğun bir imar faaliyetinin yürütüldüğü bilinmektedir. Çalışmaya konu olan başlıklar Bithynion antik kentinde de bu imparatorlar döneminde imari faaliyetlerin yoğun olarak yürütüldügüünü göstermesi açısından oldukça önemlidir.

\section{Katalog}

\begin{tabular}{|c|c|}
\hline Katalog No & $: 1$ \\
\hline Müze Env. No & $: 13$ \\
\hline Resim & $: 1-2$ \\
\hline Buluntu Yeri & : Bolu - İl Merkezi \\
\hline Ölçüleri & : Yük.: 55.7 cm., Üst Gen.: 55 cm., Alt Gen.: $37.1 \mathrm{~cm}$. \\
\hline Tarihleme & : Geç Hadrianus-Antoninus Pius \\
\hline Tanım & : Yer yer pembe ve gri damarlı mermerden korinth başlığı. Abakus levhası \\
\hline üzerinde bir dü & el ve kaldırma olmak üzere iki delikli, akanthus yapraklarında yer yer \\
\hline & athos üzerinde alt ve üst yaprak çelenkli, üst yaprak çelengi akanthus \\
\hline $\begin{array}{l}\text { yaprakları uzun, } \\
\text { çkan kaulisler } \mathrm{k}\end{array}$ & ce ve derin kanallı, yaprak dilimleri beş dişli, üst yaprak çelengi arasından \\
\hline kan kaulisler k & $\begin{array}{l}\text { ah şeklinde, kapalı yaprak demetlerini taşımakta, abakus çiçeği kalın saplı, } \\
\text { yörülmüyor. }\end{array}$ \\
\hline
\end{tabular}

Benzerleri $\quad$ : Heilmeyer 1970, Taf. 26. Lev. 3.5; İdil 1984, Lev. 11.4, 45.

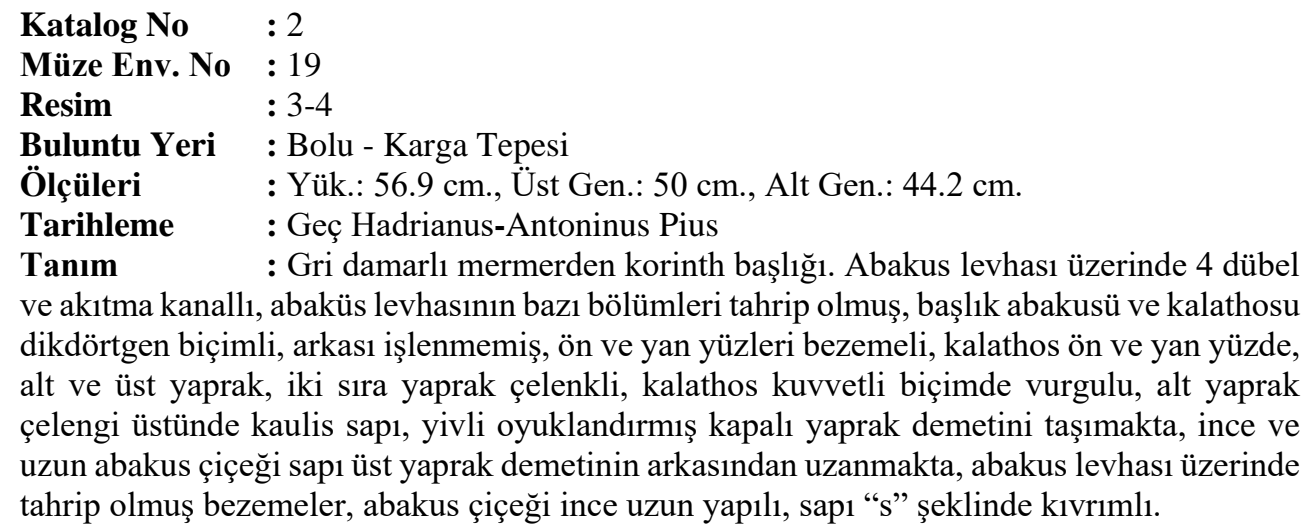
Benzerleri : Vandeput 1997, Taf. 26, 26.2, 26.3. 


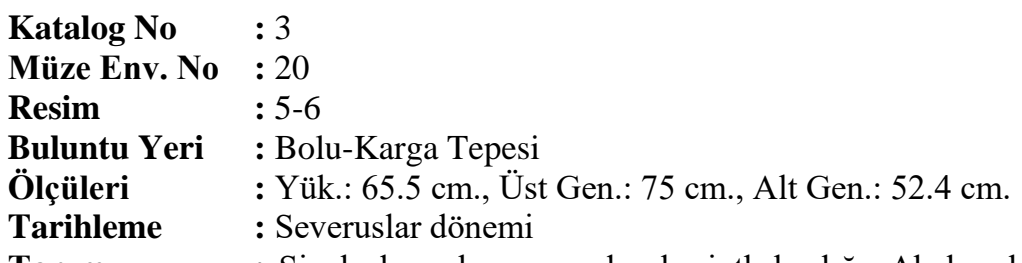

Tanım : Siyah damarlı mermerden korinth başlığı. Abakus levhası üzerinde iki adet dübel ve akıtma kanallı, iki silmeli, rozet motifli abakus levhası, abakus levhası ve kalathos yüzeyinde yer alan akanthus yaprakları tahrip olmuş, alt ve üst yaprak çelengi olmak üzere iki sıra yaprak çelenkli, kalathos ve dudağı kuvvetli biçimde yapılmış, zengin görünümlü ve kalathos tabanının altından yükselmiş derin kanallı alt yaprak sırası, üst yaprak sırası ince uzun kanallı, yaprak dilimleri arasında geniş oyuklar, üst akanthus yaprak uçları arasında üçgen şeklinde boşluklar, ince kaulis sapında açık demetler ve demetlerin üstünde kuvvetli heliksler,.

Benzerleri : Heilmeyer 1970, Taf. 31,32; Vandeput 1997, 353, Pl. 120.1-120.2; Başaran 1999, 66; Türkmen 2007, 126, Kat No. 36.
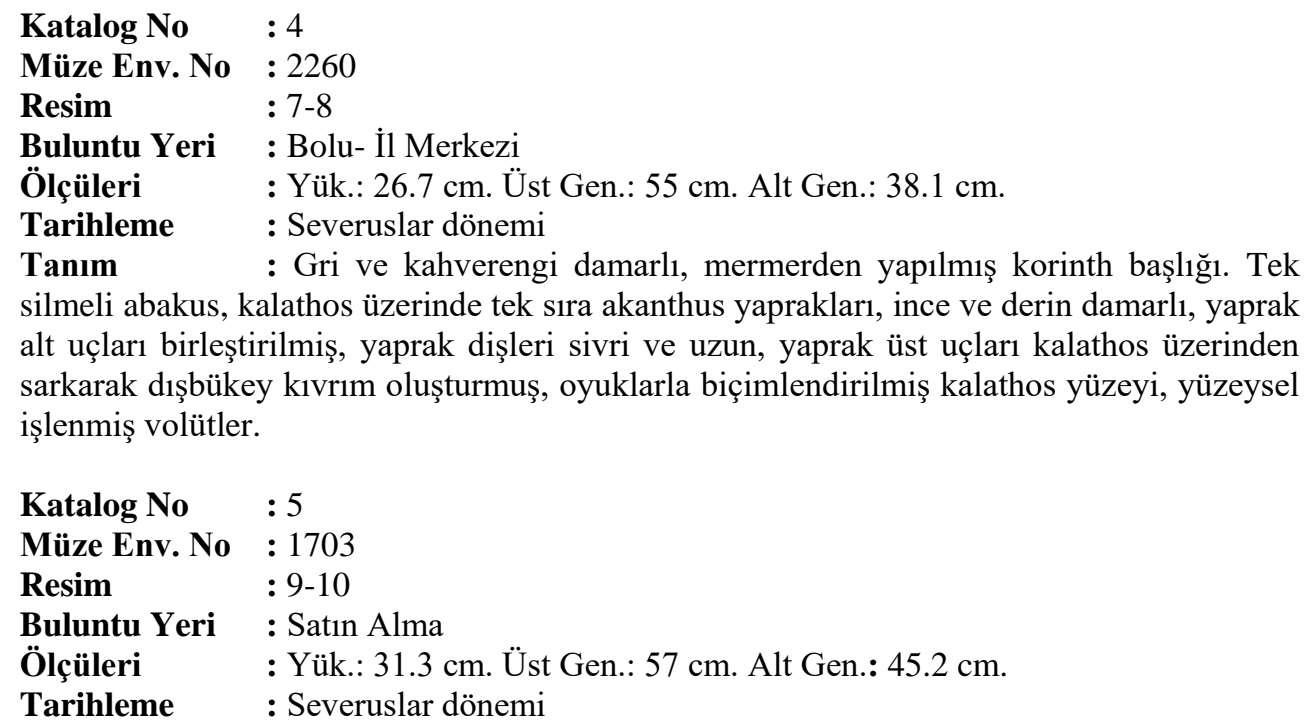

Tanım : Gri damarlı mermerden korinth başlığı. Tek silmeli abakus levhası, üstünde bir adet dübel delikli, büyük ölçüde aşınmış, kalathos yüzeyinde tek sıra halinde başlık boyutuna göre büyük tutulmuş akanthus yaprakları, alt uçları üçgen şeklinde gözlü, yaprak dişleri sivri, uzun, üst uçları kalathos üzerinden sarkarak dışbükey bir kıvrım oluşturmuş.

Benzerleri : Başaran 1999, 80, Res. 45; Türkmen 2007, 320, Lev. 68; Kaplan 2014, 7.32, Kat 2.3.

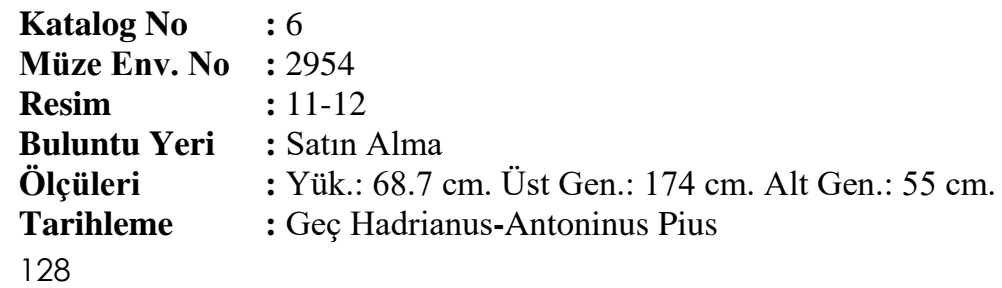


Tanım

: Kahverengi damarlı mermerden yapılmış korinth başlığı. Büyük ölçüde aşınmış abakus üç silmeli, ortada mızrak ucu betimlemeli, üstünde iki adet dübel delikli ve akıtma kanallı, kalathos yüzeyinde ikişer derin kanallı yivler ve altında iki sıra akanthus yapraklı, alt akanthus yaprakları kalathos altından ince, uzun ve derin kanallı, yaprak uçları uzun damlalar şeklinde.

Benzerleri : Vandeput 1997, 269, 339, Pl. 36.4, 106.2.

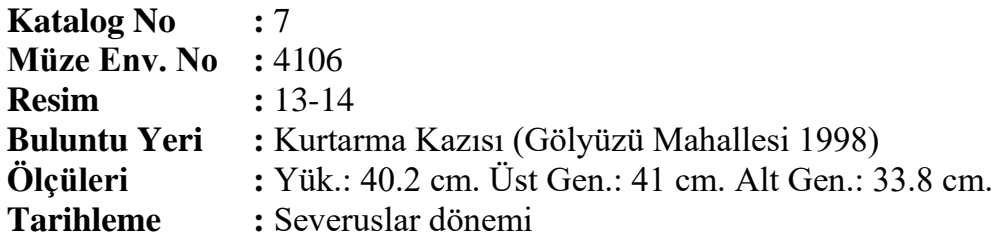

Tanım : Kahverengi damarlı mermerden yapılmış korinth başlığı. Tek silmeli abakus üstünde iki adet dübel delikli ve akıtma kanallı, oldukça aşınmış abakus, alt sıra akanthus yapraklarının damarları ince ve derin kanallı, yaprak uçlarında damla şeklinde iri gözlü, alt akanthus yapraklarına göre daha sığ ve sık işlenerek küçük tutulmuş üst sıra yaprak çelengi, üst yaprakların uçları birbirine bağlanarak üçgen şeklinde oluşturulmuş gözler, kalın tutulmuş kaulis sapı, kaulisler arasında iki figür.

Benzerleri : Başaran 1999, 72, Res. 85; Kaya 2015, 430, Res. 5.

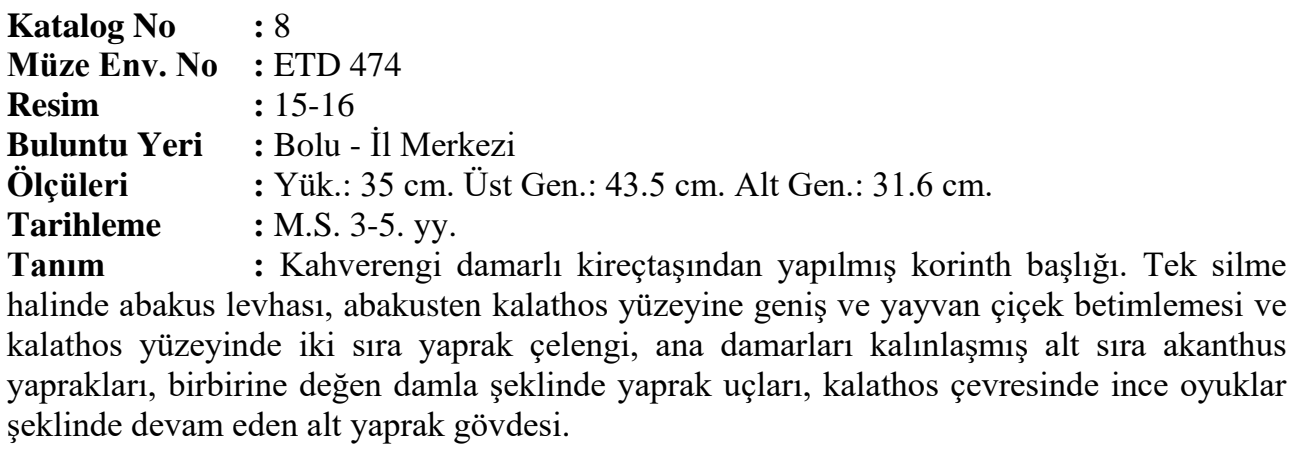

Benzerleri : Kramer 1997, Taf. 22,27, Abb. 40,50.

\section{Kaynakça}

Anabolu, M. (2016), Küçük Asya Sikkeleri Üzerindeki Mimarlık Yapıtları İle İlişkili Olan Resimler I1, Sanat Tarihi Dergisi, 2/2.

Ara, B. (1971), Anadolu'da Roma Devri Mimarisi, İ.T.Ü. Mimarlık Fakültesi, İstanbul.

Baranaydın, F. (2016), Ayasuluk Tepesi Korinth Başlıkları, (Yayımlanmamış Yüksek Lisans

Tezi) Dokuz Eylül Üniversitesi Sosyal Bilimler Enstitüsü, İzmir.

Başaran, C. (1988), Arkeolojiye Giriş I, Atatürk Üniversitesi Fen-Edebiyat Fakültesi Yayını, Erzurum.

Başaran, C. (1995), “Antik Çăg Mimarisinde Estetik Anlatım”, Atatürk Üniversitesi Güzel Sanatlar Enstitüsü Dergisi, 1, 9-14.

Başaran, C. (1997), “Kyzikos Korinth Başlıkları”, Türk Arkeoloji Dergisi, XXXI, Ankara, 152.

Başaran, C. (1999), Anadolu Kompozit Başlıkları, Arkeoloji Ve Sanat Yayınları, İstanbul. Bolu Il Yilliğg (1973), Kemal Matbaası, Bolu. 
Dimicioğlu, S. (2012), “Sebilci”, Bolu Kültür Dergisi, Sayı 2, 1-20.

Fischer, M. (1990), Das Korinthische Kapitell İm Alten Israel In Der Hellenistischen Und Römischen Periode, Mainz Am Rhein, München.

Fischer, M. (1998), Marble Studies: Roman Palestine And The Marble Trade, Uvk Universitatsverlag Konstanz, Vol. 40.

Güneş, M. Y. (2009), "Bolu İli, Merkez İlçe, Stadion Kurtarma Kazısı”, 2008, 18. Müze Çalışmaları Ve Kurtarma Kazıları Sempozyumu, Sivas, 159-174.

Güzel, E. (2007), Side Müzesi'nde Bulunan Korinth Başlıkları, (Yayımlanmamış Yüksek Lisans Tezi), Selçuk Üniversitesi Sosyal Bilimler Enstitüsü, Konya, 12-24.

He1lmeyer, W. D. (1970), Korinthische Normalkapitelle. Studien Zur Geschichte Der Römischen Architekturdekoration, Mitteilungen Des Deutschen Archäologischen Instituts, Römische Abteilung, 16. Ergänzungsheft, Heidelberg.

İdil, V. (1984), “Anadolu'da Roma İmparatorluk Çağı Korinth Başlıkları”, Anadolu XX, Ankara, 1-49.

Jones, M. W. (1991), "Designing The Roman Corinthian Capital”, Papers Of The British School At Rome, 59, England, 89-149.

Kaplan, D. (2014), "Salamis Roma Hamamı Korinth Başlıkları”, Journal Of International Social Research, Cilt 7, Say1 32, 390-403.

Kaplan, D. (2016), Tarsus Müzesi'ndeki Roma Dönemi Mimari Elemanları, Tarsus Müzesi Taş Eserleri, Serra Durugönül (Ed.), Mersin Üniversitesi Kilikia Arkeolojisini Araştırma Merkezi (Kaam) Yayınlar1- 5, İstanbul, 151-185.

Karagülle, C. (2015), “Bolu'da Antik Dönem Ve Mimari İzleri”, Abant İzzet Baysal Üniversitesi, Mühendislik Ve Mimarlık Fakültesi,1-15.

Kaya, F. H. (2015), “Soli Pompeiopolis Korinth Başlıkları”, Uluslararası Genç Bilimciler Buluşması Il: Anadolu Akdenizi Sempozyumu, 427-443.

Kaya, F. H. (2016), Soli Pompeiopolis Korinth Başlıkları, (Yayınlanmamış Doktora Tezi), Dokuz Eylül Üniversitesi, Sosyal Bilimler Enstitüsü, İzmir.

Kramer, J. (1994), Korinthische Plasterkapitelle In Kleinasien Und Konstantinopel, TüBingen.

Kramer, J. (1997), Spätantike Korinthische Säulenkapitelle In Rom, Band 3, Wiesbaden.

Marek, C. ( 2003), Bithynia Et Pontus, Philipp Von Zabern, Berlin, 2003.

Sevin, V. (2001), Anadolu'nun Tarihi Coğrafyası, Türk Tarih Kurumu Basımevi, Ankara.

Sezgin, T. (2004), Hierapolis Roma Dönemi Mimari Bezemeler, (Yayımlanmamış Yüksek Lisans Tezi) Pamukkale Ünversitesi Sosyal Bilimler Enstitüsü, Denizli.

Söğüt, B. (2005), "Ein Hellenistisches Kapitell Aus Dem Rauhen Kilikien Das Korinthische Kapitell Von Efrenk", Istanbuler Mitteilungen, 55, 157-173.

Söğüt, B. (2005), “Hierapolis Arkeloji Müzesi’ndeki Bezemeli Mimari Elamanlar M.Ö. 1. M.S. 1. Yüzyıla Ait Bezemeli Mimari Elamanlar", Ahmet Adil Tırpan Armăganı, Ege Yayınları, İstanbul, 349-371.

Şimşek, C., Sezgin M. A. (2007) “The West And North Theatres In Laodicea”, Restoration And Management Of Ancient Theatres In Turkey, Hierapolis İnternational Symposium, 103-128.

Tekin, O. (2012), Eski Yunan Ve Roma Tarihine Giriş, İletişim Yayınları, İstanbul.

Türkmen, M. (2007), Pamphylia Ve Kilikia'da Severuslar Dönemi Mimari Bezemesi, (Yayımlanmamış Doktora Tezi), İstanbul Üniversitesi Sosyal Bilimler Enstitüsü, İstanbul.

Ulugün, F. Y., Bakan, M. Ve Aksoy, T. (2007), Kocaeli Ve Çevresi Tarihi Iı (Roma Dönemi Bithynia), Kyod Yayınları, İzmit.

Umar B. (1986), Bithynia, Akbank Yayınları, İstanbul. 
Warwick W. (1889), Pontus, Paphlagonia, Bithynia, And The Kingdom Of Bosporus, A Catalogue Of The Greek Coins İn British Museum, Reginald Stuart Poole (Ed.), Printed By Order Of The Trustees, London.

Vandeput, L. (1997), The Architectural Decoration In Roman Asia Minor. Sagalassos, A Case Study, M. Wealkens (Ed.), Katholieke Universiteit Leuven Brepols Publishers, Belgium.

Vıtruvıus, (2005), Mimarlık Üzerine On Kitap, (Trans: Morris Hicky Morgan) Şevki Vanlı Mimarlık Vakfı Iv. Baskı, Ankara.

Yalman, B. (1981), “Bolu Hisartepe Kazısında Bulunan Tapınak Kalıntısı”, IX. Türk Tarih Kongresi, I. Cilt, Ankara, 435-450.

Yener, B. (2014), "The Corinthian Capitals Of Laodikeia. Scienze Dell'antichità", 20(2), $125-141$.

Yılmaz, B. (2010), Batı Anadolu Hellenistik Dönem Anta Başlıkları, (Yayımlanmamış Yüksek Lisans Tezi) Pamukkale Ünversitesi Sosyal Bilimler Enstitüsü, Denizli.

Yılmaz, B. (2012), "Stratonikei'dan Paye Başlı̆̆ı”, Ahmet Adil Tırpan Armăganı, Ege Yayınları, İstanbul, 693-700.

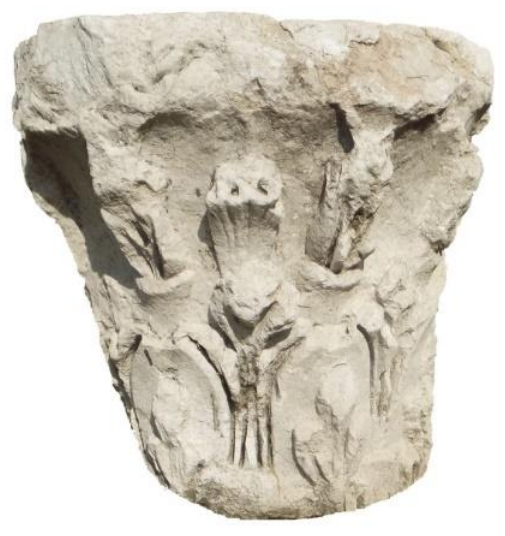

Resim 1 (Kat. No. 1)

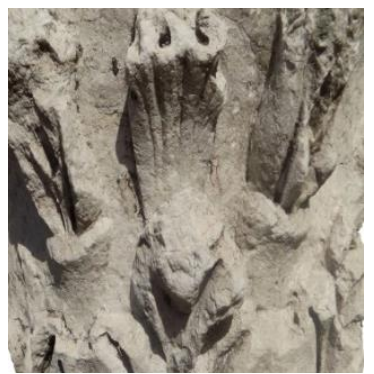

Resim 2 (Kat. No. 1) 


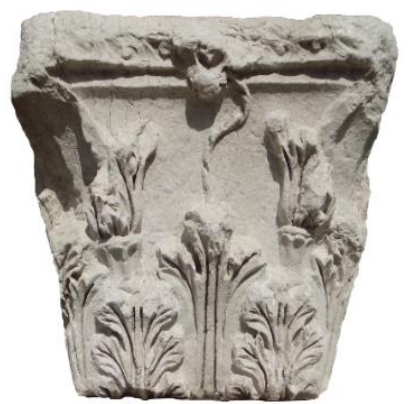

Resim 3 (Kat. No. 2)

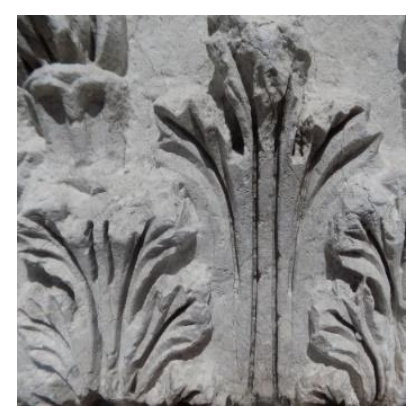

$$
\text { Resim } 4 \text { (Kat. No. 2) }
$$

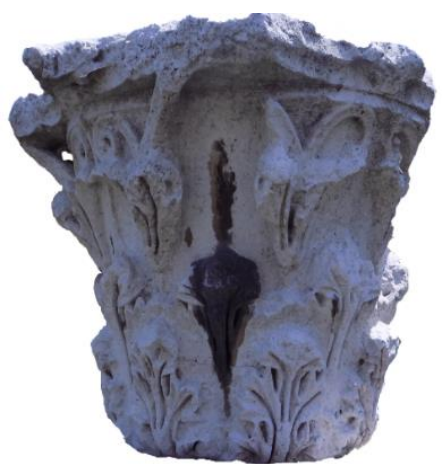

Resim 5 (Kat. No. 3)

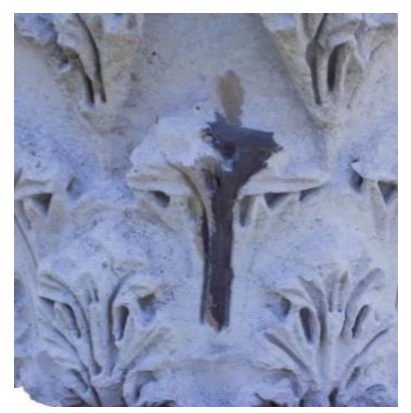




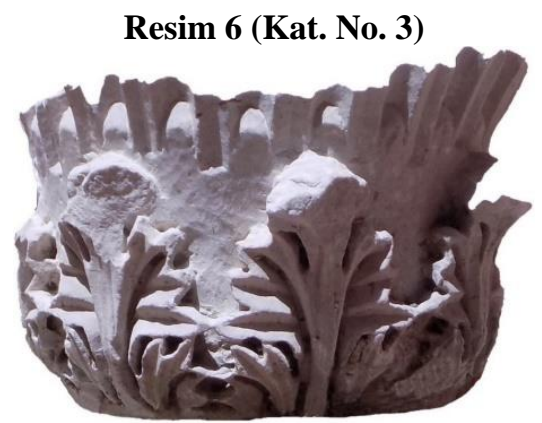

Resim 7 (Kat. No. 4)

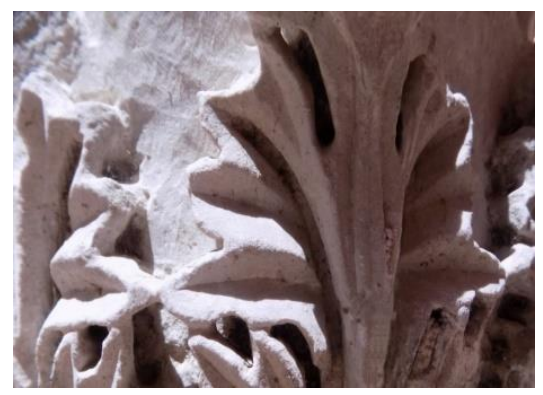

Resim 8 (Kat. No. 4)

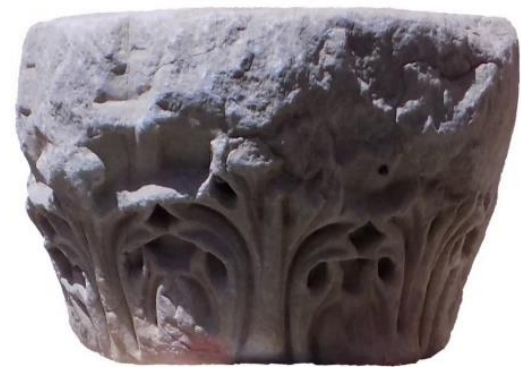

Resim 9 (Kat. No. 5)

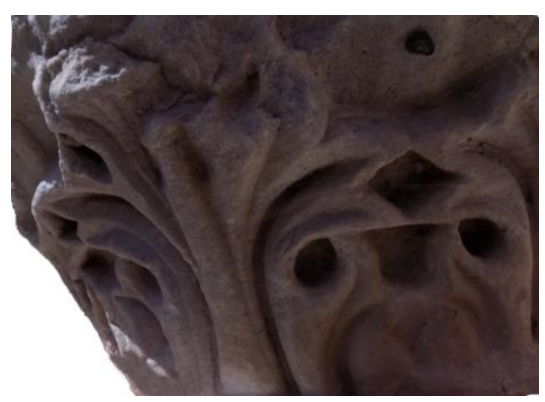

Resim 10 (Kat. No. 5) 


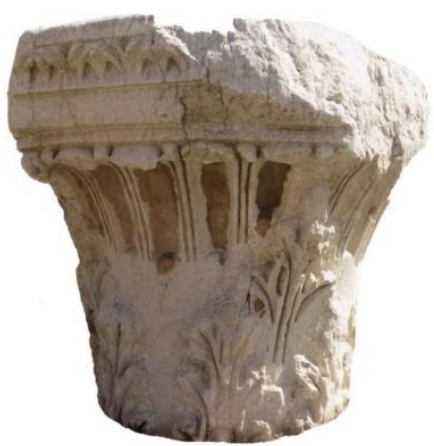

Resim 11 (Kat. No. 6)

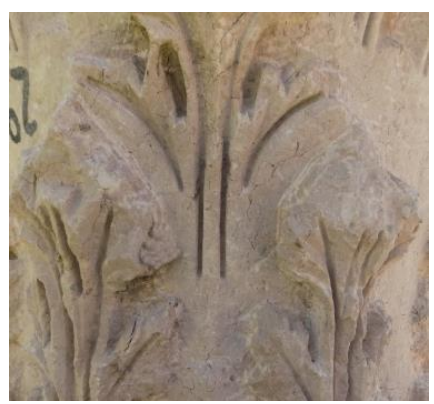

Resim 12 (Kat. No. 6)

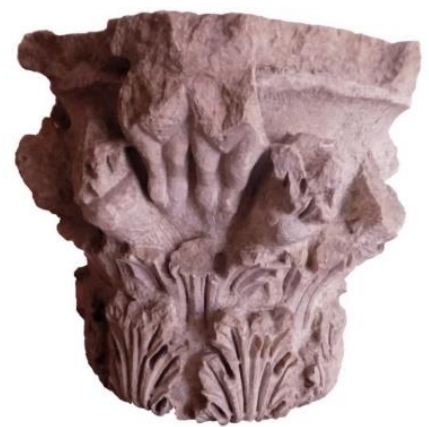

Resim 13 (Kat. No. 7)

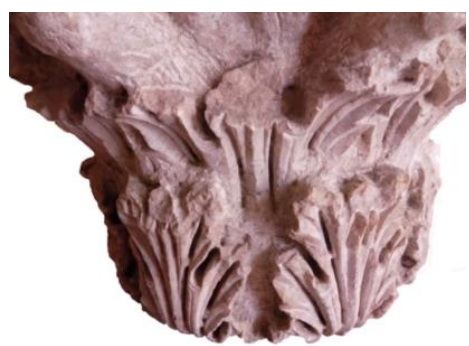

Resim 14 (Kat. No. 7) 


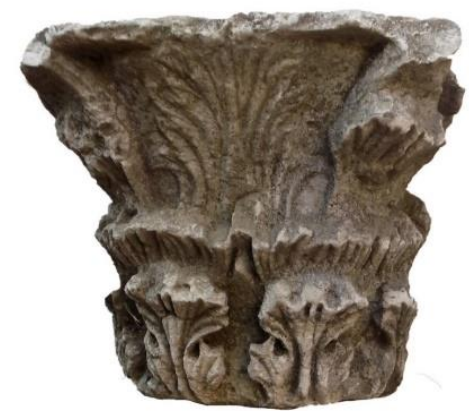

Resim 15 (Kat. No. 8)

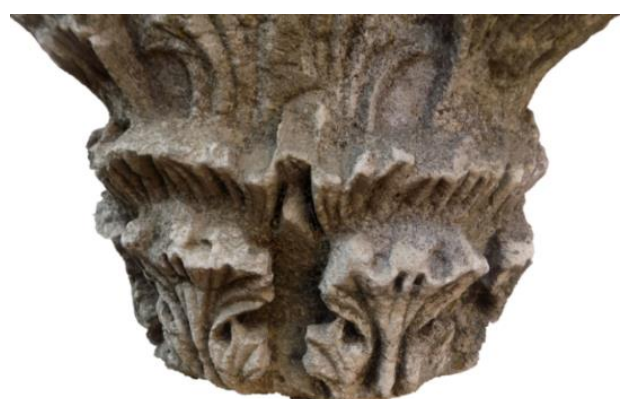

Resim 16 (Kat. No. 8) 